\title{
Life in a world with per oral endoscopic myotomy: The ever-changing landscape in management of achalasia
}

Siva Raja, MD, PhD, and Sudish C. Murthy, MD, PhD

Feature Editor's Note-Achalasia is a rare, incurable, and chronic set of debilitating diseases for which medical therapy is mostly ineffective. The aperistalsis of achalasia is currently not a productive target for therapy and effective interventions convene on targeting the lower esophageal sphincter, the muscle of which fails to relax in achalasia and precludes passage of life-sustaining nutriments. The adoption of per oral endoscopic myotomy (POEM) in recent years has expanded the menu of variably effective and variably durable endoscopic and surgical procedures that provide meaningful palliation to patients with achalasia. In this clever procedure, the inner mucosal layer of the esophagus is traversed with an endoscope and a long esophagogastric myotomy is created. We have learned that proficiency with endoscopy is requisite, that dysphagia can be relieved, and that clinically important reflux can result. In rare diseases, it is common for clinical practice standards to be based on lower level evidence and expert consensus. Likely secondary to the rapid emergence of POEM, however, 2 randomized controlled clinical trials of the treatment for achalasia were published in 2019. One trial was published in JAMA and compares POEM with pneumatic dilation (PD). One trial was published in NEJM and compares POEM with the time-honored operation of Heller myotomy and Dor fundoplication. To follow is a practical synthesis of the results of these 2 randomized trials expertly contextualized within the state of the art for achalasia therapy, and pragmatically delivered for practitioners who are seeking to improve and thoughtfully individualize care for their patients with achalasia.

\section{Bryan M. Burt, MD}

Treatment of achalasia has evolved slowly since the original description by Sir Thomas Willis (1694) of using a whale bone to propel food into the stomach. Although simple mechanical treatments continued for

\footnotetext{
From the Department of Thoracic and Cardiovascular Surgery, Heart and Vascular Institute, Cleveland Clinic Foundation, Cleveland, Ohio.

This study was funded in part by the Daniel and Karen Lee Endowed Chair in Thoracic Surgery.

Received for publication Sept 25, 2019; revisions received Dec 25, 2019; accepted for publication Jan 19, 2020; available ahead of print May 6, 2020.

Address for reprints: Siva Raja, MD, PhD, Department of Thoracic and Cardiovascular Surgery, Cleveland Clinic, 9500 Euclid Ave/Desk J4-1 Cleveland, OH 44195 (E-mail: rajas@ccf.org).

J Thorac Cardiovasc Surg 2020;160:854-7 0022-5223/ $\$ 36.00$

Copyright $(9) 2020$ Published by Elsevier Inc. on behalf of The American Association for Thoracic Surgery

https://doi.org/10.1016/j.jtcvs.2020.01.108
}

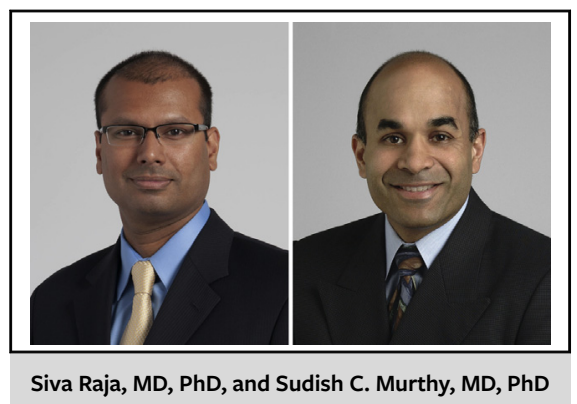

CENTRAL MESSAGE

POEM seems to be a more effective tool in treating achalasia than pneumatic dilation. But is it as good as a minimally invasive Heller myotomy?

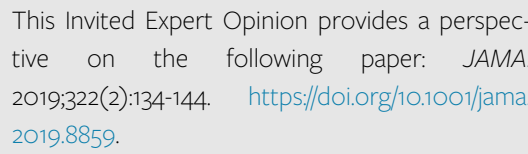

centuries, the "modern era" of achalasia therapy is best considered to have started in 1913 with the description by Ernst Heller of his surgical myotomy of the lower esophageal sphincter. ${ }^{1}$ Yet as is so often the case, it is seldom where you start something but rather where you go once you start, and for achalasia, given recent advancements in the physiologic assessment and treatment of the disease, there is little doubt that we are at a point that is unrecognizable to the original architects of its treatment. Even over the past 20 years, what was once thought to be a rarely encountered disease with fairly primitive treatment options has now become a far more easily recognized clinical entity, with numerous treatment options. This expansion of our knowledge and interventions, however, is not without controversy or complexity.

We now appreciate the spectrum of achalasia and the progression of disease with time. We understand that highresolution manometry is invaluable in guiding therapy, that the disease is not yet curable, and that customization of treatment is key and complex. The only thing the patient really cares about is relief of dysphagia and adequacy of nutrition, and this does not always correlate with objective measurements. ${ }^{2}$ This observation highlights the concept that "objective" improvement in esophageal emptying 
postintervention does not always correlate with "subjective" improvement in patient reported symptoms. This needs to remain front and center.

As patients are adept at altering their lifestyle to reduce the impact of symptoms, disease presentation is seldom early. And as with most diseases, there is usually a series of interventions to be considered, each escalating in complexity, invasiveness, and ultimately, morbidity. It is the job of the clinician to understand where (and when) each fits into the current management of achalasia, and hopefully not assume that the latest one is the best one.

\section{CURRENT TREATMENTS FOR ACHALASIA}

Clinicians must appreciate that achalasia is a systemic disease (ultimately involving much of the esophagus), starting as a seemingly simple and straightforward mechanical problem of incomplete relaxation at the lower esophageal sphincter. As such, medical therapy focuses on relaxation or paralysis and relies on a limited number of medications (calcium channel blockers and nitrates) and botulinum toxin. ${ }^{3,4}$ A brief respite from symptoms may be observed, but is without a durable effect, unfortunately. These types of interventions might best be considered diagnostic, particularly trial of botulinum toxin, or as the last line of palliation when all else has failed.

Despite the description of a surgical myotomy before the advent of minimally invasive techniques, dilation (especially PD to 30,35 , and $40 \mathrm{~mm}$ ) was the mainstay of therapy given the morbidity of the open surgical approach (left thoracotomy). PD has a lengthy track record detailing its safety and importantly its efficacy. It is the modality against which minimally invasive Heller myotomy, and more recently POEM are compared. However, the most effective first treatment for achalasia continues to been hotly debated.

In their recently published randomized controlled trial, Ponds and colleagues ${ }^{5}$ compare the short-term efficacy of PD (30-mm and 35-mm balloon) with POEM as the first treatment for achalasia. In this study, 66 patients were randomized to PD and 67 to POEM. Primary treatment success, as characterized by an Eckardt score 3 or less, was achieved in $92 \%$ of patients receiving POEM and 54\% receiving PD at 2 years. This difference started to become evident even at 3 months after initial treatment, with PD success at $80 \%$ versus $98 \%$ for POEM. The authors conclude that POEM should dethrone PD as the optimal initial treatment for patients with achalasia.

\section{IMPLICATIONS}

The study by Ponds and colleagues ${ }^{5}$ sheds light on the value of a myotomy versus dilation, with apparent benefits even in the early post-treatment period after POEM. Although discussed in the body of the work, some curious methodological choices and findings will be sure to result in further debate about the utility of this study. Primarily, the authors' choice to not use a $40-\mathrm{mm}$ balloon and more than $50 \%$ of the patients being male can be thought of as contributing to the lowered efficacy of PD. Other randomized controlled trials including some of the authors from the current study showed $86 \%$ success at 2 years $(82 \%$ at 5 years) for PD when the $40-\mathrm{mm}$ balloon was used and not the $54 \%$ success at 2 years in the current study. ${ }^{5-7}$

Concluding that POEM is preferred over PD raises the issue of patient access to physicians skilled in POEM as a late confounder. Most patients with achalasia are first diagnosed by their gastroenterologists and as such are likely to receive endoscopic treatment first. Given that PD is commonly performed, there already exists a pathway for practitioners to gain expertise in this procedure. POEM is, however, a far more complex endoscopic procedure with additional potential for significant complications, ${ }^{8}$ particularly in inexperienced hands. Courses are held routinely to introduce physicians to POEM using a porcine or cadaveric model bearing limited resemblance to the real thing. Our own data would suggest a learning curve continues for as many as 100 cases. ${ }^{9}$ In the study by Ponds and colleagues, ${ }^{5}$ it is hard to ascertain the previous experience of the participating centers and their selection criteria. Additionally, the average number of POEM or PD might only be 3 to 4 patients per year per center (66-67 patients from 6 centers over 3 years) if every patient seen was enrolled. At present, POEM is generally performed in high-volume centers with low morbidity and mortality. When performed in lowvolume centers, complications such as perforations and bleeding, along with incomplete myotomy, would be expected to be more common. We are seeing an increasing number of patients referred with incomplete palliation of dysphagia after POEM, as well as late peptic strictures despite proton-pump inhibitor therapy (Figure 1) that need additional interventions after only a few years from their index procedure.

The last but perhaps the most significant finding of postoperative reflux and esophagitis also highlighted by Ponds and colleagues ${ }^{5}$ seems inescapable. The authors note that $41 \%$ of patients had reflux esophagitis after POEM. This is consistent with the recently published meta-analysis by Schlottmann and colleagues, ${ }_{10}^{10}$ who report gastroesophageal reflux disease (GERD) in $47.5 \%$ of patients. Given that achalasia is a benign condition in which life expectancy is not usually dictated by the disease after adequate treatment, follow-up is measured in terms of 5, 10, and 15 years or longer. Short follow-up of 2 years is clearly inadequate, and sequelae such as esophagitis can have significant cumulative morbidity over the course of a patient's lifetime and must be considered.

Given that palliation of dysphagia is the primary goal, we, as a field, would have been content with the state of 


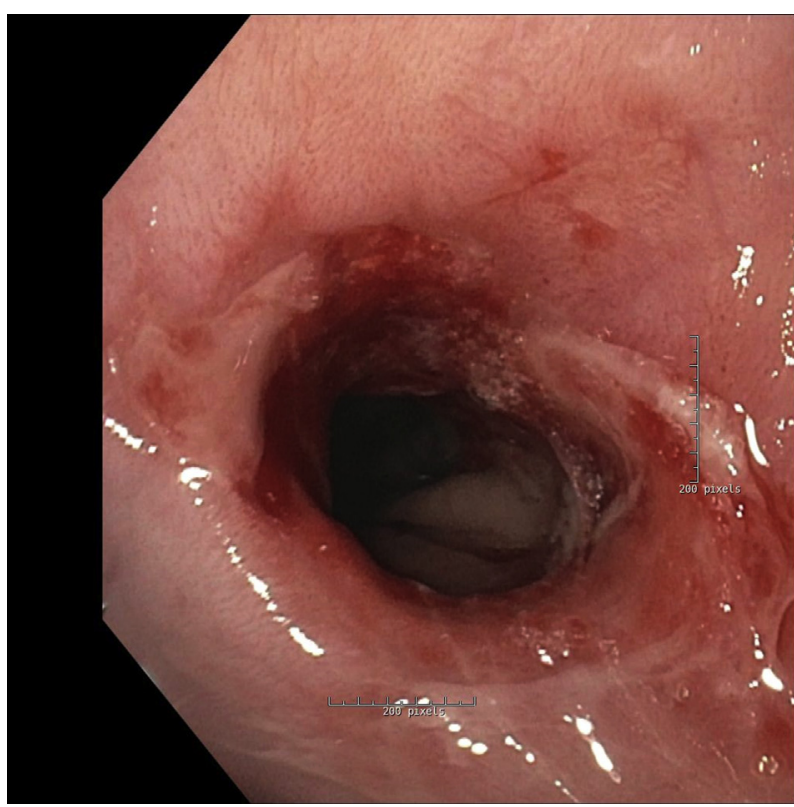

FIGURE 1. Endoscopic image of a peptic stricture in a patient receiving proton-pump inhibitor therapy after POEM.

affairs if a better option did not exist. Alas, one does exist: minimally invasive Heller myotomy with a partial fundoplication. In the same meta-analysis by Schlottman and colleagues, ${ }^{10}$ they found just an $11 \%$ risk of GERD after a minimally invasive Heller myotomy with fundoplication. Two- and 5-year "success" of Heller myotomy were $89 \%$ and $84 \%$, respectively. ${ }^{6}$ A 10 -year comparison of PD to Heller myotomy showed a $47.9 \%$ versus $79.6 \%$ rate of palliation, respectively, ${ }^{11}$ although not all of the dilations were done with the Rigiflex balloon and the largest of the contributing studies ${ }^{12}$ did not have the balloon type. Therefore, the obvious omission is the additional comparison of POEM and PD with Heller myotomy. This may be due to a commonly held bias that PD is the gold standard. The term "gold standard" usually refers to an ideal treatment with high efficacy and low morbidity. In this case, one can argue that it should be a minimally invasive Heller myotomy with a Dor fundoplication, not PD.

\section{WHAT SHOULD BE THE REAL STUDY?}

In light of all of this, the efficacy of Heller myotomy versus POEM should be the main debate. Long-term data suggest that long-term, surgical myotomy is superior to PD in terms of symptom palliation without need for reintervention. As such, most clinicians will no longer have the clinical equipoise to further study that comparison. Given the long history of Heller myotomy as well as the increasing popularity of POEM, a true randomized controlled trial is needed to determine the ideal treatment for achalasia. And as if on cue, shortly after the publication by Ponds and colleagues, ${ }^{5}$ the study of POEM versus Heller myotomy for achalasia was published. ${ }^{13}$
Werner and colleagues ${ }^{13}$ reported their results from a small randomized controlled study comparing POEM (112 patients) to Heller myotomy with a Dor fundoplication (109 patients) from 8 centers. They noted that at 2 years the success rates (as measured by Eckardt score $<$ or $=3$ ) were $83 \%$ for POEM and $82 \%$ for Heller myotomy. They conclude noninferiority of POEM to Heller myotomy, yet other outcomes suggest that this might be premature. The rates of esophagitis was nearly triple $(57 \%$ for POEM and $20 \%$ for LHM) at 1 year. It was curious that there was a somewhat smaller difference in 2 years but more importantly, without any difference in the rate of abnormal $\mathrm{pH}$ studies (30\% in each group).

As in the study by Ponds and colleagues, ${ }^{5}$ the study by Werner and colleagues ${ }^{13}$ only shows 2-year follow-up when 5- to 10-year data are more meaningful, especially given the high rate of esophagitis in the POEM group. Both studies had $8 \%$ to $19 \%$ of patients who were type III for whom PD and Heller myotomy have historically had limited success.

Rare chronic diseases are challenging to study with randomized control trials. A prospective multi-institutional granular database may allow for comparisons without affecting equipoise among physicians who have their own respective bias. Additionally, the effect of GERD after POEM will require long-term follow-up to determine whether complications such as stricture, Barrett esophagus, and cancer are real concerns. It would also demonstrate, as we have shown, that there is a low but finite time-dependent failure rate that may require patients to undergo reintervention to assist symptom palliation. ${ }^{14}$ The idea of any intervention for patients with achalasia as a "one-and-done" event needs to be challenged.

\section{TRUTH USUALLY LIES IN THE MIDDLE}

Albert Einstein once said that "as our circle of knowledge expands, so does the circumference of darkness surrounding it." The current studies are no exception as we are left with more questions. Each of the aforementioned procedures have their respective advantages and as such have a place in the armamentarium of an "achalasia therapist." An algorithm of balanced approach was suggested by our group in a recent publication on managing patients with achalasia. ${ }^{9}$ Type II achalasia with a normal esophageal morphology and patients with hiatal hernia seem to do well with a Heller myotomy and fundoplication. Patients with sink-trap esophagus appear to have some palliation from Heller myotomy (but likely without a fundoplication). Patients with type III achalasia seem to do well with POEM while having poor palliation with Heller myotomy. POEM and PD are well suited to salvage patients with a prior myotomy. Patients who are poor surgical candidates still benefit from PD or botulinum toxin injections. 
In the future, patients with achalasia will likely have an earlier diagnosis, more access to experienced physicians who commonly treat achalasia, and long-term follow-up to maintain palliation. They will most certainly be treated with the optimal therapy wherein each of these modalities, and those that have yet to be innovated, has a role in their treatment algorithm. In regard to this debate, Winston Churchill said it best about how "this is not the end. It is not even the beginning of the end. But it is, perhaps, the end of the beginning."

\section{Conflict of Interest Statement}

Dr Raja is a consultant for Smiths Medical. Dr Murthy has nothing to disclose with regard to commercial support.

\section{References}

1. Payne WS. Heller's contribution to the surgical treatment of achalasia of the esophagus. 1914. Ann Thorac Surg. 1989;48:876-81.

2. Zanoni A, Rice TW, Lopez R, Birgisson S, Shay SS, Thota PN, et al. Timed barium esophagram in achalasia types. Dis Esophagus. 2015;28:336-44.

3. Bansal R, Nostrant TT, Scheiman JM, Koshy S, Barnett JL, Elta GH, et al. Intrasphincteric botulinum toxin versus pneumatic balloon dilation for treatment of primary achalasia. J Clin Gastroenterol. 2003;36:209-14.

4. Bruley des Varannes S, Scarpignato C. Current trends in the management of achalasia. Dig Liver Dis. 2001;33:266-77.

5. Ponds FA, Fockens P, Lei A, Neuhaus H, Beyna T, Kandler J, et al. Effect of peroral endoscopic myotomy vs pneumatic dilation on symptom severity and treatment outcomes among treatment-naive patients with achalasia: a randomized clinical trial. JAMA. 2019;322:134-44.

6. Moonen A, Annese V, Belmans A, Bredenoord AJ, Bruley des Varannes S, Costantini M, et al. Long-term results of the European achalasia trial: a multicentre randomised controlled trial comparing pneumatic dilation versus laparoscopic Heller myotomy. Gut. 2016;65:732-9.

7. Boeckxstaens GE, Annese V, des Varannes SB, Chaussade S, Costantini M, Cuttitta A, et al. Pneumatic dilation versus laparoscopic Heller's myotomy for idiopathic achalasia. N Engl J Med. 2011;364:1807-16.

8. Haito-Chavez Y, Inoue H, Beard KW, Draganov PV, Ujiki M, Rahden BHA, et al. Comprehensive analysis of adverse events associated with per oral endoscopic myotomy in 1826 patients: an international multicenter study. Am J Gastroenterol. 2017;112:1267-76.

9. Raja S, Murthy SC, Tang A, Siddiqui HU, Parikh MP, Ahmad U, et al. Per oral endoscopic myotomy: another tool in the toolbox. J Thorac Cardiovasc Surg. 2019; 158:945-51.

10. Schlottmann F, Luckett DJ, Fine J, Shaheen NJ, Patti MG. Laparoscopic Heller myotomy versus peroral endoscopic myotomy (POEM) for achalasia: a systematic review and meta-analysis. Ann Surg. 2018;267: 451-60

11. Weber CE, Davis CS, Kramer HJ, Gibbs JT, Robles L, Fisichella PM. Medium and long-term outcomes after pneumatic dilation or laparoscopic Heller myotomy for achalasia: a meta-analysis. Surg Laparosc Endosc Percutan Tech. 2012;22:289-96.

12. Inoue H, Minami H, Kobayashi Y, Sato Y, Kaga M, Suzuki M, et al. Peroral endoscopic myotomy (POEM) for esophageal achalasia. Endoscopy. 2010;42: 265-71.

13. Werner YB, Hakanson B, Martinek J, Repici A, von Rahden BHA, Bredenoord AJ, et al. Endoscopic or surgical myotomy in patients with idiopathic achalasia. N Engl J Med. 2019;381:2219-29.

14. Raja S, Schraufnagel DP, Blackstone EH, Murthy SC, Thota PN, Thuita L, et al Reintervention after Heller myotomy for achalasia: is it inevitable? Ann Thorac Surg. 2019;107:860-7. 